\title{
The British Rhinology Society National COVID-19 Study: Resuming Elective Surgery*
}

\section{Sridhayan Mahalingam', Richard Green², Mohd Afiq Mohd Slim³, Anton Alatsatianos ${ }^{3}$, Yujay Ramakrishnan ${ }^{4}$, Ben Stew ${ }^{5}$, Claire Hopkins ${ }^{1}$ on behalf of 245 collaborative authors}

Rhinology Online, Vol 4: 36 - 48, 2021

http://doi.org/10.4193/RHINOL/21.004

*Received for publication:

February 9, 2021

Accepted: March 10, 2021

Published: March 21, 2021

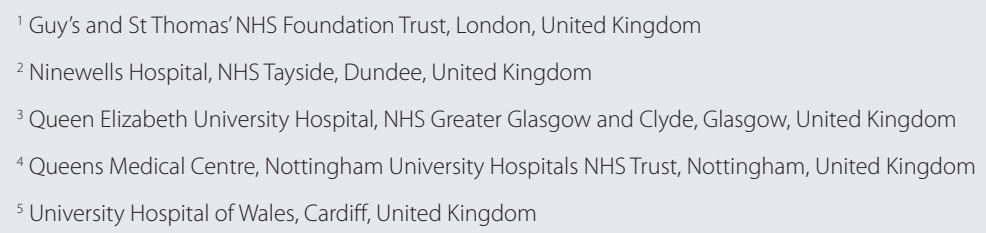

\begin{abstract}
Background: As elective services resumed in the aftermath of the first wave of the SARS-CoV-2 pandemic, the British Rhinology Society and Juniors Committees carried out a national prospective study in order to assess and optimise safety and efficacy of surgery.
\end{abstract}

Methodology: Data from 1063 cases was collected from 111 centres in the United Kingdom (excluding Northern Ireland) within the study period (1st June - 14th August 2020), and a three week follow-up period to assess whether there were any cases of SARS-CoV-2 amongst patients and staff.

Results: $89.2 \%$ of procedures took place in England. $90.6 \%$ of patients had minimal comorbidities (ASA Grade 1 or 2). $98.4 \%$ of patients were known to have a COVID negative status prior to surgery, with the majority (99.8\%) investigated through Viral PCR alone. The most common form of pre-operative shielding was to self-isolate for 14 days ( $82.5 \%$ of cases). $32.6 \%$ of cases were performed in an alternative theatre environment, and in $5.3 \%$ the private sector was used for NHS patients. In $21.6 \%$ of procedures, unfamiliar anaesthetic teams were used, and in 19.2\% unfamiliar theatre teams. There was a higher probability of unfamiliar theatre staff or anaesthetist, when operating in an alternative theatre environment. Trainees were not present in theatre in $24.2 \%$ of cases. Full PPE (Personal Protective Equipment) was worn by the operating surgeon in $64.1 \%$ of cases. No patients or staff were reported to have developed SARS-CoV-2 in the three week period following surgery. Intra-operative challenges were reported in $19.7 \%$ of cases and were primarily associated with impaired communication (8.8\%) or impaired vision (6.9\%). There was a higher chance of challenges reported when unfamiliar theatre teams were present.

Conclusions: This data suggests that overall, the resumption of rhinological elective services has been performed safely with no cases of SARS-CoV-2 reported in patients or staff. We must consider the challenges of operating in unfamiliar environments together with surgical and/or anaesthetic teams, as well as the impact on training.

Key words: rhinology, elective surgery, COVID

\section{Introduction}

The SARS-CoV-2 pandemic has significantly impacted upon the provision of services in healthcare systems throughout the world. In the United Kingdom, in view of the need to prioritise resources whilst protecting emergency and cancer services during the first wave of the pandemic, cases were initially risk stratified $^{(1,2)}$, and those deemed to be low priority either cancelled or postponed. 
Although it has since been confirmed that this was incorrectly reported, an initial case from Wuhan whereby 14 theatre staff members were allegedly infected following transsphenoidal pituitary surgery raised considerable alarm over potential aerosolisation of the virus when performing rhinological surgery ${ }^{(3,4)}$.

As fatalities began to plateau ${ }^{(5)}$, reducing the need for reallocation of resources and the waiting times for elective operating increased $^{(6)}$; there became a stronger emphasis on the resumption of routine elective activity ${ }^{(7)}$. Simultaneously, our understanding of the disease process continues to improve in order to try and undertake this with minimal risk.

In May 2020, NHS England published their roadmap to safely bring back elective activity ${ }^{(8)}$. This framework included the need for careful planning, rigorous monitoring and continuous improvement. However, the results of a survey of 1741 surgeons in June 2020 commissioned by the Royal College of Surgeons of England ${ }^{(9)}$, highlighted significant challenges in re-starting elective surgery, which included a lack of capacity in interdependent services (46\%), lack of staff (35\%), lack of access to testing, and insufficient PPE (21\%).

The British Rhinological Society (BRS) and BRS Juniors' councils highlighted the need to monitor safety during the recommencement of rhinological operating.

\section{Aims and objectives}

The aim of this study was to collect prospective data to assess the safety and challenges encountered when initiating elective rhinological surgery in the United Kingdom following the first wave of the pandemic. Specific objectives included addressing the following:

- When and where are we performing elective rhinological surgery?

- Documentation of the morbidity and mortality associated with elective rhinology operating during a pandemic

- What is the current practice with respect to:

o Pre-operative testing

o Personal protective equipment

o Use of specific equipment

- How has training being affected?

- What challenges do surgeons face?

\section{Materials and methods}

Data collection

A prospective multicentre audit was conducted over from the 1st of June 2020 to 14th August 2020 for all elective rhinological surgery. Involvement was approved at each centre as a quality improvement project and anonymised data was collected by local ENT teams using a predefined data collection tool (Appendix
1). This included patient characteristics, surgical intervention, use of personal protective equipment (PPE), and complications inclusive of post-operative COVID-19 infection up to three weeks in the postoperative period.

\section{Categorical variable stratification}

Surgical operations were classified into 4 categories (Appendix

2): Diagnostic, Functional, Cancer (histologically confirmed), and Other. Meanwhile, ethnic categories were reclassified into Caucasian versus Non-Caucasian due to the small subset of other ethnicities in this category.

\section{Statistical methodology}

Numerical data were tested with the Shapiro-Wilks test to evaluate the data distribution. The Kruskal-Willis Rank Sum test (kw) was conducted for non-normally distributed data and reported as the median and interquartile range. Categorical data were analysed with the Pearson's Chi-squared test $\left(\chi^{2}\right)$ or Fisher's exact test ( $\mathrm{f}$ ). A p-value of $\leq 0.05$ was set as the statistically significant value. Odds ratios were calculated where associations were explored between the variables of interest. The R version 4.0.3 (2020-10-10) software was used with the associated packages: Tidyverse $^{(10)}$, compareGroup ${ }^{(11)}$, dplyr ${ }^{(12)}$, ggplot $2^{(13)}$ lubridate $^{(14)}$.

\section{Results}

Basic demographics

Overall, 111 centres in 16 regions in the United Kingdom (excluding Northern Ireland) responded. Fifteen centres reported no elective rhinological surgery during the duration of this audit. From the remaining 96 centres, 1063 procedures were captured during the audit period (Table 1, Figure 1); the proforma had been fully completed in $84 \%$ of cases.

The median age at time of procedure was 47.0 years [IQR: 31.0 ; 60.0] with those who underwent surgery for cancer being the oldest; median age of 53.0 years [IQR: 45.5;64.0]. Male gender was most predominant $(59.8 \%)$ and $94.1 \%$ of procedures were performed on adults; those aged $17-49$ years being the predominant subgroup (49.2\%). With regards to ethnicity, there were no statistically significant difference between our cohort of patients and the UK population ${ }^{(15)}$ between Caucasians and non-Caucasians $(p=0.06)$.

The mean number of rhinological procedures performed in the UK on a week-by-week basis was $88.6 \pm 45.8$ (equivalent to 18.0 cases \pm 9.9 per day). The majority of procedures were performed in England (89.2\%), followed by Scotland (9.2\%) and Wales (1.6\%). Figure 2 shows the cumulative workload in each nation and Figure 3 shows the types of procedures performed, with functional procedures the most common. 


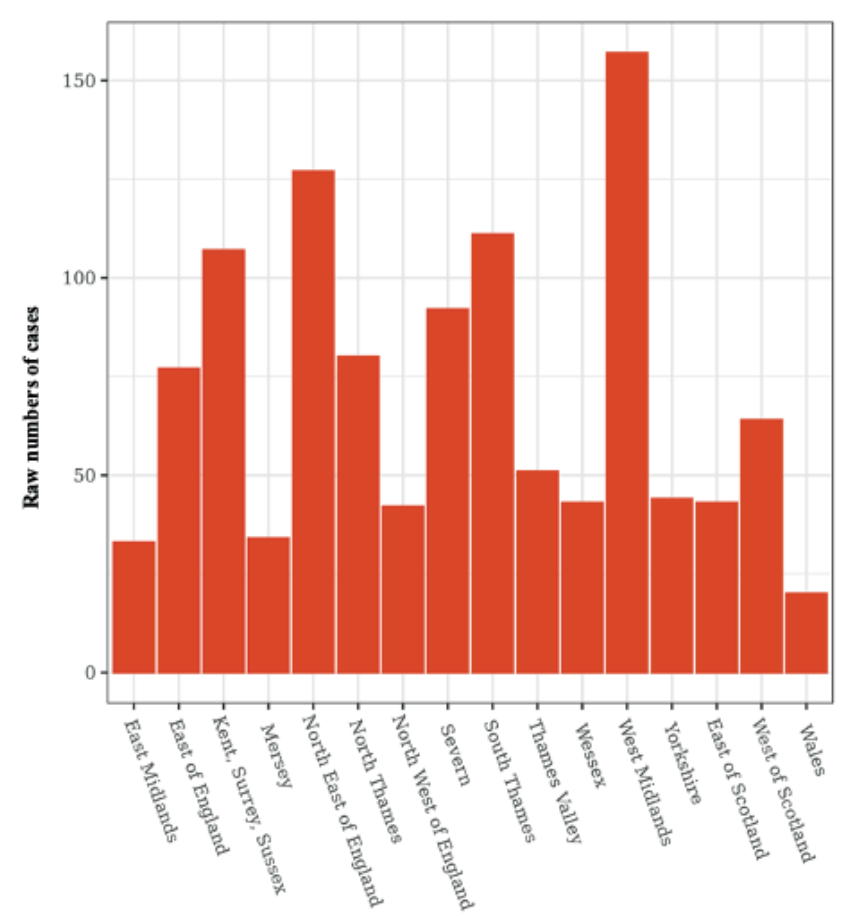

Figure 1. Number of operative procedures performed in each region.

\section{Comorbidities}

The majority of patients (90.6\%) had minimal comorbidities and were categorised as either ASA grade 1 and 2 (Table 2) (16). For those with respiratory disease, the odds of having functional procedures were statistically high (OR: 1.89, $\mathrm{p}<0.001$ ).

\section{Pre-operative COVID-19 status and management}

1046 (98.4\%) of patients were known to have a COVID negative status prior to surgery, with the vast majority (99.8\%) undergoing Viral PCR through a nasal/nasopharyngeal swab. Two further patients also underwent imaging in the form a chest radiograph (Table 3). In the remaining 17 (1.6\%) cases the COVID status was not reported. The most common form of pre-operative shielding was for patients to self-isolate for a 14 day period prior to surgery (82.5\%). 83 patients (7.83\%) were reported as having not self-isolated, of whom the majority underwent functional (41\%) and diagnostic (36.1\%) surgery.

No patients or staff tested positive for COVID-19 at the end of the 3-week follow-up period.

\section{Familiarity of surgical environment}

Almost one third (32.6\%) of operations were carried out in an alternative operating theatre environment, whether this was a different theatre setting within the same hospital (13.8\%), or in another hospital altogether (18.8\%; Table 4). There were 5.27\% of NHS cases being undertaken in the private healthcare system. Whilst $56.4 \%$ of functional procedures were carried out in a

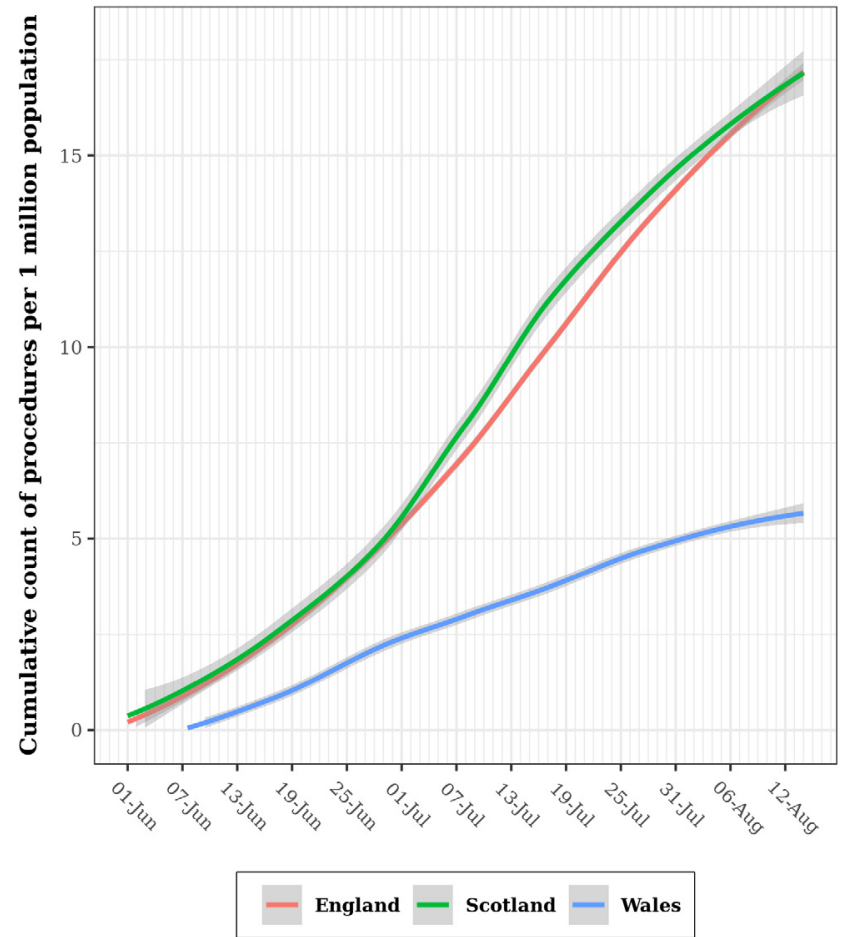

Figure 2. Changes in capacity over time. The nations effect.

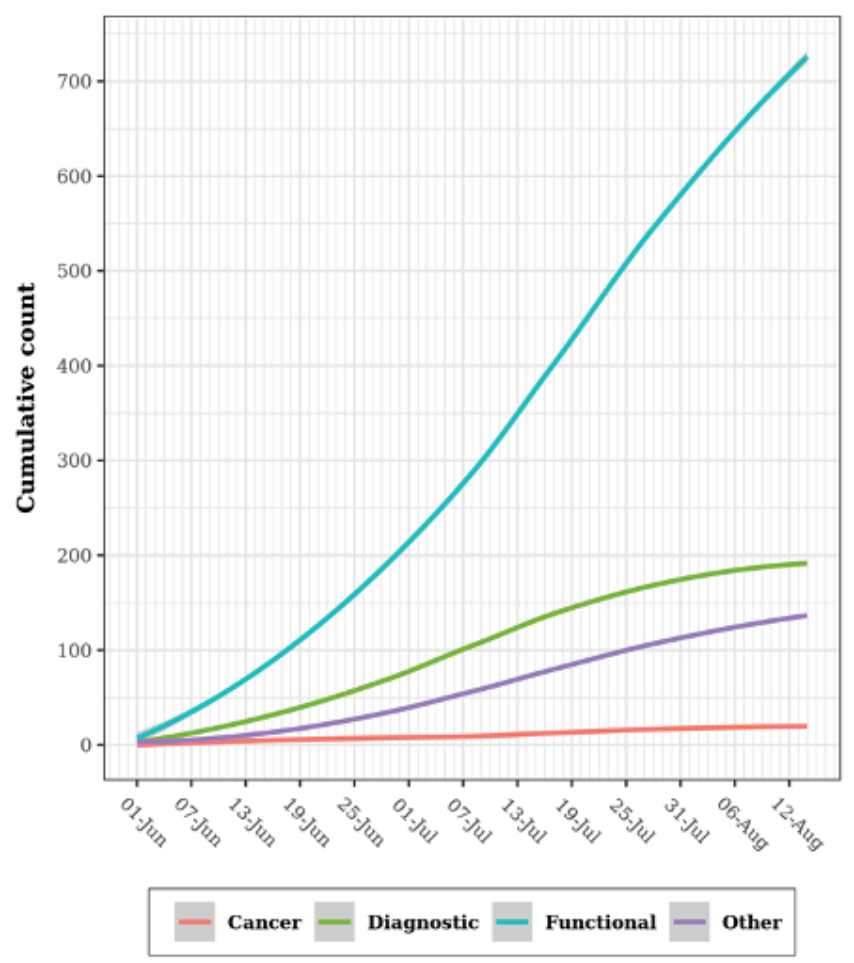

Figure 3. Changes in capacity over time. The operative procedures effect.

hospital with a "COVID-free" status (OR: 1.69 [95\% Cl:1.30;2.19], $\mathrm{p}<0.001$ ), this was only the case with $39.7 \%$ of diagnostic procedures and $20 \%$ of cancer surgery. Unfamiliar anaesthetists were 
Table 1. Basic demographics.

\begin{tabular}{|c|c|c|c|c|c|}
\hline & $\begin{array}{c}\text { [ALL] } \\
N=1063\end{array}$ & $\begin{array}{l}\text { Cancer } \\
\mathrm{N}=20\end{array}$ & $\begin{array}{l}\text { Diagnostic } \\
\qquad \mathrm{N}=194\end{array}$ & $\begin{array}{l}\text { Functional } \\
\qquad \mathrm{N}=714\end{array}$ & $\begin{array}{l}\text { Other } \\
\mathrm{N}=135\end{array}$ \\
\hline \multicolumn{6}{|l|}{ Gender: } \\
\hline Female & $427(40.2 \%)$ & $7(35.0 \%)$ & $92(47.4 \%)$ & $268(37.5 \%)$ & $60(44.4 \%)$ \\
\hline Male & $636(59.8 \%)$ & $13(65.0 \%)$ & $102(52.6 \%)$ & $446(62.5 \%)$ & $75(55.6 \%)$ \\
\hline Age (year old) & $47.0[31.0 ; 60.0]$ & $53.0[45.5 ; 64.0]$ & $47.5[28.0 ; 59.8]$ & $47.0[32.0 ; 60.0]$ & $42.0[30.0 ; 60.0]$ \\
\hline \multicolumn{6}{|c|}{ Age Category (year old): } \\
\hline$\leq 16$ & $62(5.83 \%)$ & $0(0.00 \%)$ & $32(16.5 \%)$ & $14(1.96 \%)$ & $16(11.9 \%)$ \\
\hline $17-49$ & $523(49.2 \%)$ & $9(45.0 \%)$ & $72(37.1 \%)$ & $377(52.8 \%)$ & $65(48.1 \%)$ \\
\hline $50-59$ & 199(18.7\%) & $3(15.0 \%)$ & $41(21.1 \%)$ & $136(19.0 \%)$ & 19(14.1\%) \\
\hline $60-69$ & $161(15.1 \%)$ & $7(35.0 \%)$ & $22(11.3 \%)$ & $113(15.8 \%)$ & $19(14.1 \%)$ \\
\hline$\geq 70$ & $118(11.1 \%)$ & $1(5.00 \%)$ & $27(13.9 \%)$ & $74(10.4 \%)$ & $16(11.9 \%)$ \\
\hline \multicolumn{6}{|l|}{ Ethnic Group: } \\
\hline Caucasian & $915(86.2 \%)$ & $18(90.0 \%)$ & $171(88.1 \%)$ & $617(86.5 \%)$ & $109(80.7 \%)$ \\
\hline Non-Caucasian & $147(13.8 \%)$ & $2(10.0 \%)$ & $23(11.9 \%)$ & $96(13.5 \%)$ & $26(19.3 \%)$ \\
\hline \multicolumn{6}{|l|}{ Month: } \\
\hline June & $311(29.3 \%)$ & $8(40.0 \%)$ & 74(38.1\%) & $193(27.0 \%)$ & $36(26.7 \%)$ \\
\hline July & $629(59.2 \%)$ & $10(50.0 \%)$ & $105(54.1 \%)$ & $428(59.9 \%)$ & $86(63.7 \%)$ \\
\hline August & $123(11.6 \%)$ & $2(10.0 \%)$ & $15(7.73 \%)$ & $93(13.0 \%)$ & $13(9.63 \%)$ \\
\hline \multicolumn{6}{|l|}{ Nation: } \\
\hline England & $948(89.2 \%)$ & $14(70.0 \%)$ & $153(78.9 \%)$ & $657(92.0 \%)$ & $124(91.9 \%)$ \\
\hline Scotland & $98(9.22 \%)$ & $6(30.0 \%)$ & $32(16.5 \%)$ & $51(7.14 \%)$ & $9(6.67 \%)$ \\
\hline Wales & $17(1.60 \%)$ & $0(0.00 \%)$ & $9(4.64 \%)$ & $6(0.84 \%)$ & $2(1.48 \%)$ \\
\hline
\end{tabular}

involved in $21.6 \%$ of cases. Meanwhile, $19.2 \%$ of cases involved unfamiliar theatre teams. The odds of an unfamiliar anaesthetist (OR: 5.28 [95\% Cl 3.87;7.26], $\mathrm{p}<0.001$ ) and theatre teams (OR: 15.7 [95\% Cl 10.8;23.5], p<0.001) increased significantly if procedures were performed in other places than the usual location.

\section{Personal protective equipment and utilisation of powered} instrumentation

Full PPE (defined as using both an FFP3 mask/Powerhood or PAPR (Powered Air Purifying Respirator) in conjunction with eye protection; Table 5) was reported to have been worn in $64.1 \%$ of the procedures. Full PPE was used by $44.8 \%$ of anaesthetists and $48.6 \%$ of theatre teams. With respect to the use of powered instrumentation, a powered microdebrider was used in $38.5 \%$ of cases, and a powered drill in $7.62 \%$ (Table 5). When powered instrumentation was utilised, the operating surgeons were noted to have worn full PPE in $68.1 \%$ of cases. The use of powered instruments did not significantly statistically change over time.

\section{Impact on training}

Trainees were not present in theatre for $24.2 \%$ of procedures (Table 6). Overall, they were involved in $72 \%$ of procedures, of which the largest cohort was part performing the procedure with trainer scrubbed (STS).

\section{Challenges and outcomes reported}

Intra-operative challenges were reported in $19.7 \%$ of cases, with the largest proportion of issues being communication in theatre (8.84\%) followed by impaired vision (6.87\%) due to the use of PPE (Table 7). There was a significant increase in challenges reported when the theatre team was unfamiliar (OR: 1.54 [95\% Cl 1.06;2.21], p:0.023).

There was a total of $63(5.9 \%)$ reported complications in the data set. Complications were divided into separate categories: epistaxis, post-operative infection, orbital injury, cerebrospinal fluid leak and other (Figure 4). The most common complication was epistaxis ( $n=34)$, with the requirement for blood transfusion in two cases, and no requirement for further surgical intervention. Infection was reported in 10 cases with one septal abscess returning to theatre for washout. 5 instances of orbital complications were reported, 4 orbital fat exposure, with no visual sequelae reported thereafter, and one case unspecified. 3 cerebrospinal fluid leaks were reported. One case occurred during functional endoscopic sinus surgery for inverted papilloma surgery, and was repaired intra-operatively with no further sequelae. There were two cases following transsphenoidal fenestration of an 
Table 2. Comorbidities.

\begin{tabular}{|c|c|c|c|c|c|}
\hline & $\begin{array}{c}\text { [ALL] } \\
\mathrm{N}=1063\end{array}$ & $\begin{array}{l}\text { Cancer } \\
\mathrm{N}=\mathbf{2 0}\end{array}$ & $\begin{array}{c}\text { Diagnostic } \\
\qquad \mathrm{N}=194\end{array}$ & $\begin{array}{l}\text { Functional } \\
\qquad N=714\end{array}$ & $\begin{array}{l}\text { Other } \\
\mathrm{N}=135\end{array}$ \\
\hline \multicolumn{6}{|c|}{ ASA: } \\
\hline 1 & $495(47.5 \%)$ & $5(25.0 \%)$ & $99(52.4 \%)$ & $330(47.1 \%)$ & $61(46.2 \%)$ \\
\hline 2 & $449(43.1 \%)$ & $11(55.0 \%)$ & $71(37.6 \%)$ & $316(45.1 \%)$ & $51(38.6 \%)$ \\
\hline 3 & $95(9.12 \%)$ & $4(20.0 \%)$ & 19(10.1\%) & $53(7.56 \%)$ & $19(14.4 \%)$ \\
\hline 4 & $3(0.29 \%)$ & $0(0.00 \%)$ & $0(0.00 \%)$ & $2(0.29 \%)$ & $1(0.76 \%)$ \\
\hline \multicolumn{6}{|c|}{ Cardiovascular Disease: } \\
\hline No & $883(83.1 \%)$ & $15(75.0 \%)$ & 159(82.0\%) & $600(84.0 \%)$ & 109(80.7\%) \\
\hline Yes & $180(16.9 \%)$ & $5(25.0 \%)$ & $35(18.0 \%)$ & $114(16.0 \%)$ & $26(19.3 \%)$ \\
\hline \multicolumn{6}{|c|}{ Respiratory Disease: } \\
\hline No & $908(85.4 \%)$ & $18(90.0 \%)$ & $179(92.3 \%)$ & $593(83.1 \%)$ & $118(87.4 \%)$ \\
\hline Yes & $155(14.6 \%)$ & $2(10.0 \%)$ & $15(7.73 \%)$ & $121(16.9 \%)$ & $17(12.6 \%)$ \\
\hline \multicolumn{6}{|c|}{ Previous History of Malignancy: } \\
\hline No & 1044(98.2\%) & 19(95.0\%) & 186(95.9\%) & 706(98.9\%) & 133(98.5\%) \\
\hline Yes & 19(1.79\%) & $1(5.00 \%)$ & $8(4.12 \%)$ & $8(1.12 \%)$ & $2(1.48 \%)$ \\
\hline \multicolumn{6}{|c|}{ Diabetes Mellitus: } \\
\hline No & 1018(95.8\%) & 19(95.0\%) & 187(96.4\%) & $684(95.8 \%)$ & $128(94.8 \%)$ \\
\hline Yes & $45(4.23 \%)$ & $1(5.00 \%)$ & $7(3.61 \%)$ & $30(4.20 \%)$ & $7(5.19 \%)$ \\
\hline
\end{tabular}

Table 3. COVID status and pre-operative management.

\begin{tabular}{|lc|}
\hline & $\begin{array}{c}\text { [ALL] } \\
\text { N=1063 }\end{array}$ \\
\hline Pre-Operative Self-Isolation Period: & \\
\hline 7-Days & $30(2.83 \%)$ \\
\hline 14-Days & $875(82.5 \%)$ \\
\hline Other & $72(6.79 \%)$ \\
\hline Did Not Self-Isolate & $83(7.83 \%)$ \\
\hline Type Of COVID-19 Test: & \\
\hline Combination & $2(0.19 \%)$ \\
\hline Viral PCR \& Imaging & $1044(99.8 \%)$ \\
\hline Viral PCR & \\
\hline
\end{tabular}

arachnoid cyst $(n=2)$. Eleven complications were classified as other; restenosis of choanal atresia repair $(n=2)$, neurological complications $(n=3)$, intolerable pain $(n=1)$, suture granuloma $(n=1)$, low sodium (pituitary surgery) $(n=1)$, septal perforation $(n=1)$, nasal crusting $(n=1)$ and migration of nasal packing into the oropharynx $(n=1)$. There was one mortality due to an anaesthetic complication.

\section{Discussion}

This national study provides us with data on the initiation of rhinological surgery following the first wave of the SARS-CoV-2 pandemic in the United Kingdom and its impact. Overall, 1063 patients were included from 96 centres. The distribution across England and Scotland is reflective of their respective populations from the Office of National Statistics, with a smaller data catchment noted from Wales $(1.6 \% \text { vs } 4.9 \%, p<0.001)^{(17)}$.

\section{Patient selection}

The high proportion of rhinological surgery that is undertaken for functional reasons $(67.17 \%)$ is reflected in our data. This would be categorised as lower priority according to national guidance provided by ENTUK ${ }^{(2)}$ and the Federation of Surgical Specialty Associations ${ }^{(18)}$, and was therefore postponed during the height of the pandemic. Throughout the course of the duration of the study, as elective services resume, a higher proportion of functional rhinological surgery occurred (Figure 3). The majority of this (56\%) was being performed in COVID free centres.

We also see that the majority of patients $(90.6 \%)$ who underwent rhinological surgery had minimal comorbidities (ASA grade 1 or 2). A higher proportion (20\%) of those undergoing cancer surgery were ASA 3 or 4 with only $7.8 \%$ of those undergoing functional surgery being ASA grades 3 or 4 . This suggests that patients deemed to be at higher risk were likely to be postponed wherever possible. The association between those undergoing functional surgery and respiratory disease is reflective of the known association between sinonasal disease and asthma ${ }^{(19)}$. 
Table 4. Familiarity of surgical environment.

\begin{tabular}{|lc|} 
& [ALL] \\
\hline Hospital setting: & N=1063 \\
\hline Usual location & \\
\hline Alternative within same hospital & $716(67.4 \%)$ \\
\hline Different hospital & $147(13.8 \%)$ \\
\hline Service utilization: & $200(18.8 \%)$ \\
\hline NHS Hospital & \\
\hline Private hospital & $1007(94.7 \%)$ \\
\hline Hospital COVID-19 free status: & $56(5.27 \%)$ \\
\hline No & \\
\hline Yes & $503(47.9 \%)$ \\
\hline Operation duration: & $547(52.1 \%)$ \\
\hline 60 mins or less & \\
\hline $61-120$ mins & $467(45.5 \%)$ \\
\hline $121-180$ mins & $409(39.9 \%)$ \\
\hline 181 mins or longer & $109(10.6 \%)$ \\
\hline Length of stay: & $41(4.00 \%)$ \\
\hline 12 hours or less & \\
\hline $13-24$ hours & $831(79.8 \%)$ \\
\hline $25-48$ hours & $121(11.6 \%)$ \\
\hline 49 hours or longer & $35(3.36 \%)$ \\
\hline Anaesthetist: & $55(5.28 \%)$ \\
\hline Familiar & \\
\hline Unfamiliar & $819(78.4 \%)$ \\
\hline Theatre team: & $225(21.6 \%)$ \\
\hline Familiar & \\
\hline Unfamiliar & \\
\hline
\end{tabular}

\section{Familiarity of surgical environment}

Approximately one third of procedures were performed in an alternative theatre setting, and in one fifth of patients with an unfamiliar anaesthetic and/or theatre team. Unsurprisingly our data shows that it was statistically likely that if surgery occurred in a different theatre setting then one would be operating with a different theatre team. This can impact the surgeon in a number of ways and we have shown there was a significant increase in challenges reported when the theatre team was unfamiliar (OR: 1.54 [95\% Cl 1.06;2.21], p:0.023). Furthermore, as with every surgical subspecialty, rhinological surgery requires specific anaesthetic considerations during the operative period ${ }^{(20)}$, and this is likely to be at its optimum with an anaesthetist most familiar with the surgical procedure.

\section{Testing, PPE and complications}

It was useful to know that the vast majority of patients (98.4\%)

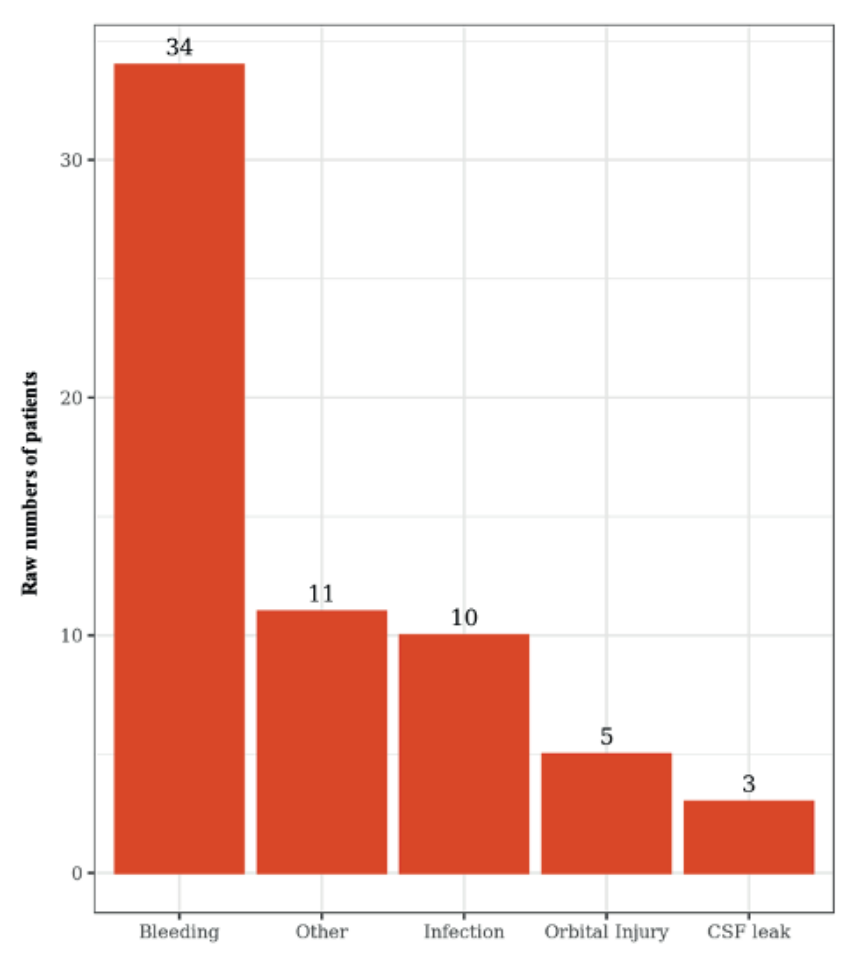

Figure 4. Complications by category.

were assessed to be COVID negative, primarily through Viral PCR and the majority of patients (82.5\%) self-isolated for a fourteen day period.

With regards to personal protection in theatre, full PPE was used by $64.1 \%$ of surgeons. Adequate PPE is important ${ }^{(21,22)}$. However, full PPE may not be required for all patients. National guidance provided by Public Health England advises that patients should be risk stratified ${ }^{(23)}$, and surgeons undertaking procedures in those who are deemed to be low risk for example can use a surgical mask, and eye protection if necessary. This is particularly important to note due to the challenges reported with the use of PPE (communication issues (8.84\%) and visual issues (6.87\%)). There were no reports of shortage of PPE for staff members.

One of the main outcomes of this audit was to assess patient and staff safety regarding elective rhinological operating, specifically with respect to viral transmission. Significantly, there were no reported cases of SARS-CoV-2 in patients or staff members post procedure. This suggests that compliance with the current guidance regarding testing and PPE facilitates safe practice with respect to elective rhinological surgery. Further evidence based guidance as we increase our understanding of the disease process is useful|(24,25).

The rate of complications overall was 5.9\%. This is comparable to previous literature ${ }^{(26,27)}$, and once again highlights the fact that 
Table 5. Personal protective equipment and utilisation of powered instrumentation.

\begin{tabular}{|c|c|c|c|c|c|}
\hline & $\begin{array}{c}\text { [ALL] } \\
\mathrm{N}=1063\end{array}$ & $\begin{array}{l}\text { Cancer } \\
\mathbf{N}=\mathbf{2 0}\end{array}$ & $\begin{array}{c}\text { Diagnostic } \\
\qquad N=194\end{array}$ & $\begin{array}{l}\text { Functional } \\
\qquad N=714\end{array}$ & $\begin{array}{l}\text { Other } \\
\mathrm{N}=135\end{array}$ \\
\hline \multicolumn{6}{|c|}{ Surgeons mask protection: } \\
\hline Not specified & $225(21.2 \%)$ & $6(30.0 \%)$ & $41(21.1 \%)$ & $156(21.8 \%)$ & $22(16.3 \%)$ \\
\hline Surgical mask & $64(6.02 \%)$ & $2(10.0 \%)$ & $16(8.25 \%)$ & $34(4.76 \%)$ & $12(8.89 \%)$ \\
\hline FFP2 & $7(0.66 \%)$ & $0(0.00 \%)$ & $1(0.52 \%)$ & $6(0.84 \%)$ & $0(0.00 \%)$ \\
\hline FFP3 & $767(72.2 \%)$ & $12(60.0 \%)$ & $136(70.1 \%)$ & $518(72.5 \%)$ & $101(74.8 \%)$ \\
\hline \multicolumn{6}{|l|}{ Eye protection: } \\
\hline No & $195(18.3 \%)$ & $3(15.0 \%)$ & $28(14.4 \%)$ & $137(19.2 \%)$ & $27(20.0 \%)$ \\
\hline Yes & $868(81.7 \%)$ & $17(85.0 \%)$ & $166(85.6 \%)$ & $577(80.8 \%)$ & $108(80.0 \%)$ \\
\hline \multicolumn{6}{|l|}{ Full PPE: } \\
\hline Not specified & $160(15.5 \%)$ & $5(26.3 \%)$ & $31(16.7 \%)$ & $108(15.6 \%)$ & $16(11.9 \%)$ \\
\hline No & $211(20.4 \%)$ & $4(21.1 \%)$ & $36(19.4 \%)$ & $137(19.7 \%)$ & $34(25.4 \%)$ \\
\hline Yes & $662(64.1 \%)$ & $10(52.6 \%)$ & $119(64.0 \%)$ & $449(64.7 \%)$ & $84(62.7 \%)$ \\
\hline \multicolumn{6}{|c|}{ Anaesthetic mask protection: } \\
\hline Not specified & $361(34.0 \%)$ & $8(40.0 \%)$ & $66(34.0 \%)$ & $241(33.8 \%)$ & $46(34.1 \%)$ \\
\hline Surgical mask & $43(4.05 \%)$ & $1(5.00 \%)$ & $12(6.19 \%)$ & $18(2.52 \%)$ & $12(8.89 \%)$ \\
\hline FFP2 & $8(0.75 \%)$ & $0(0.00 \%)$ & $1(0.52 \%)$ & $7(0.98 \%)$ & $0(0.00 \%)$ \\
\hline FFP3 & $651(61.2 \%)$ & $11(55.0 \%)$ & $115(59.3 \%)$ & $448(62.7 \%)$ & $77(57.0 \%)$ \\
\hline \multicolumn{6}{|l|}{ Eye protection: } \\
\hline Not specified & $452(42.5 \%)$ & $13(65.0 \%)$ & $94(48.5 \%)$ & $291(40.8 \%)$ & $54(40.0 \%)$ \\
\hline Yes & $611(57.5 \%)$ & $7(35.0 \%)$ & $100(51.5 \%)$ & $423(59.2 \%)$ & $81(60.0 \%)$ \\
\hline \multicolumn{6}{|l|}{ Full PPE: } \\
\hline Not specified & $536(50.4 \%)$ & $12(60.0 \%)$ & $100(51.5 \%)$ & $358(50.1 \%)$ & $66(48.9 \%)$ \\
\hline No & $51(4.80 \%)$ & $1(5.00 \%)$ & $13(6.70 \%)$ & $25(3.50 \%)$ & $12(8.89 \%)$ \\
\hline Yes & $476(44.8 \%)$ & $7(35.0 \%)$ & $81(41.8 \%)$ & $331(46.4 \%)$ & $57(42.2 \%)$ \\
\hline \multicolumn{6}{|c|}{ Theatre team mask protection: } \\
\hline Not specified & $249(23.4 \%)$ & $9(45.0 \%)$ & $44(22.7 \%)$ & $167(23.4 \%)$ & $29(21.5 \%)$ \\
\hline Surgical mask & $65(6.11 \%)$ & $0(0.00 \%)$ & $15(7.73 \%)$ & $41(5.74 \%)$ & $9(6.67 \%)$ \\
\hline FFP2 & $12(1.13 \%)$ & $0(0.00 \%)$ & $1(0.52 \%)$ & $11(1.54 \%)$ & $0(0.00 \%)$ \\
\hline FFP3 & $737(69.3 \%)$ & $11(55.0 \%)$ & $134(69.1 \%)$ & $495(69.3 \%)$ & $97(71.9 \%)$ \\
\hline \multicolumn{6}{|l|}{ Eye protection: } \\
\hline Not specified & $476(44.8 \%)$ & $15(75.0 \%)$ & $92(47.4 \%)$ & $314(44.0 \%)$ & $55(40.7 \%)$ \\
\hline Yes & $587(55.2 \%)$ & $5(25.0 \%)$ & $102(52.6 \%)$ & $400(56.0 \%)$ & $80(59.3 \%)$ \\
\hline \multicolumn{6}{|l|}{ Full PPE: } \\
\hline Not specified & $469(44.1 \%)$ & $15(75.0 \%)$ & $86(44.3 \%)$ & $313(43.8 \%)$ & $55(40.7 \%)$ \\
\hline No & $77(7.24 \%)$ & $0(0.00 \%)$ & $16(8.25 \%)$ & $52(7.28 \%)$ & $9(6.67 \%)$ \\
\hline Yes & $517(48.6 \%)$ & $5(25.0 \%)$ & $92(47.4 \%)$ & $349(48.9 \%)$ & $71(52.6 \%)$ \\
\hline \multicolumn{6}{|l|}{ Drill: } \\
\hline No & $982(92.4 \%)$ & $17(85.0 \%)$ & 192(99.0\%) & $653(91.5 \%)$ & $120(88.9 \%)$ \\
\hline Yes & $81(7.62 \%)$ & $3(15.0 \%)$ & $2(1.03 \%)$ & $61(8.54 \%)$ & $15(11.1 \%)$ \\
\hline \multicolumn{6}{|l|}{ Microdebrider: } \\
\hline No & $654(61.5 \%)$ & $10(50.0 \%)$ & 177(91.2\%) & $361(50.6 \%)$ & $106(78.5 \%)$ \\
\hline Yes & $409(38.5 \%)$ & $10(50.0 \%)$ & $17(8.76 \%)$ & $353(49.4 \%)$ & $29(21.5 \%)$ \\
\hline \multicolumn{6}{|l|}{ Visual aids: } \\
\hline Non-endoscopic & $230(23.9 \%)$ & $5(27.8 \%)$ & $39(23.2 \%)$ & $145(22.3 \%)$ & $41(33.1 \%)$ \\
\hline Endoscopic & $731(76.1 \%)$ & $13(72.2 \%)$ & 129(76.8\%) & $506(77.7 \%)$ & $83(66.9 \%)$ \\
\hline
\end{tabular}


Table 6. Trainee involvement.

\begin{tabular}{|cc|}
\hline & [ALL] \\
& N=1063 \\
\hline Trainee: & \\
\hline No trainee & $252(24.2 \%)$ \\
\hline Observed & $39(3.74 \%)$ \\
\hline Assisted & $139(13.3 \%)$ \\
\hline Supervised scrubbed (STS) & $366(35.1 \%)$ \\
\hline Supervised unscrubbed (STU) & $140(13.4 \%)$ \\
\hline Performed (P) & $106(10.2 \%)$ \\
\hline
\end{tabular}

despite challenges faced, elective rhinological surgery is being performed safely in the United Kingdom.

\section{Training and skill retention}

In a quarter of cases, trainees were not present in theatre. This highlights some of the issues surrounding the role of junior doctors during the pandemic. The pressure on the medical workforce during the COVID pandemic, together with increased staff sickness, resulted in many junior doctors being redeployed ${ }^{(28)}$. Furthermore, the risk of aerosolisation and the need for a quicker turnover of patients due to limited hospital capacity, often resulted in trainees being less involved. This is compounded by the small number of rhinological procedures performed in a day between all three nations (minimum: 1 case a day, median: 17 cases a day, maximum: 39 cases a day) which could potentially impact upon overall exposure to rhinological procedures. The Joint Committee of Surgical Training has published guidance for trainees to maximise the opportunities available ${ }^{(29)}$.

\section{Limitations}

This is the largest study performed to investigate the current experience in rhinological procedures during the SARS-CoV-2 pandemic. The limitations of our audit are primarily associated with data collection and its quality. The majority of data was collected by trainees, and this does introduce some bias as some procedures that trainees were not directly involved in may not have been captured. There was a follow-up at three weeks to determine whether patients had acquired COVID-19, however it is likely that such data would have been challenging to assess accurately due to the logistical difficulties associated with following up all members of staff, and the rate of untested, minimally symptomatic, or false negative COVID cases. Hence the possibility that some of this data may not have been included should be taken into account.

\section{Conclusions and considerations for the future}

This study suggests that the initiation of elective rhinological
Table 7. Intra-operative challenges.

\begin{tabular}{lc|}
\hline [ALL] & N=1063 \\
\hline Challenges: & \\
\hline No & $827(80.3 \%)$ \\
\hline Yes & $203(19.7 \%)$ \\
\hline Communication issues: & \\
\hline No comments & $969(91.2 \%)$ \\
\hline Yes & $94(8.84 \%)$ \\
\hline Vision issues: & \\
\hline No comments & $990(93.1 \%)$ \\
\hline Yes & $73(6.87 \%)$ \\
\hline
\end{tabular}

surgery within the United Kingdom in the aftermath of the first SARS-CoV-2 pandemic has been safe with no significant increase in complications noted. Furthermore, there is no evidence to indicate a high rate of SARS-CoV-2 cases being contracted as a direct result of surgery. The use of pre-operative testing and PPE plays an important role in managing the risk involved. PPE should be used as recommended; however it can pose visual and communication issues. Where possible, it would be useful to perform surgery with familiar anaesthetists and theatre staff with experience in rhinological surgery; however, should capacity in the NHS reduce, there may be better utilisation of the private healthcare setting for less complex surgery, preferably with experienced teams. Lastly, it is important to consider the impact on training posed by the pandemic, and wherever possible, training should be facilitated and other methods of surgical training be explored.

\section{Authorship contribution}

\section{Manuscript formatting: Mentes Zorba}

Regional leads: East Midlands, Adam Gaunt; East of England, Sheneen Meghji; Kent Surrey \& Sussex, Sridhayan Mahalingam; Mersey, Hussein Walijee; North East, Mohammed Bahgat; North Thames, Vikas Acharya; North West, Rajeev Advani; Scotland East, Richard Green; Scotland West, Mohd Afiq Mohd Slim; South Thames, Abigail Walker; South West, Ram Balakumar; Thames Valley, Ayeshah Abdul-Hamid; Wales, Pranter Brahmabhatt; Wessex, Stephen Hayes; West Midlands, Peter Deutsch; Yorkshire, Eugene Omakobia.

Hospital Site Leads: Alder Hey Children's NHS Foundation Trust, Emma Hogg, Ravi Sharma; Aneurin Bevan University Health Board, Pranter Brahmabhatt; Barking, Havering and Redbridge University Hospitals NHS Trust, Usama Ahmed, Ahmed Eweiss; Barts Health NHS Trust, Santdeep Paun, Anna Slovick; Betsi Cadwaladr University Health Board, Jake Ahmed, Richard 
Brown, Edward Flook; Birmingham Women's and Children's NHS Foundation Trust, Adnan Darr, Ann-Louise McDermott; BMI The Priory Hospital, Birmingham, Paresh Naik; Bolton NHS Foundation Trust, Vikas Malik, Sara Timms; Bradford Teaching Hospitals NHS Foundation Trust, Raad Glore, Eugene Omakobia, Jack Sandeman; Brighton and Sussex University Hospitals NHS Trust, Sridhayan Mahalingam, James Anthony McGilligan, John Michael O'Connell; Calderdale and Huddersfield NHS Foundation Trust, Khaled Diab, Anand Goomany; Cambridge University Hospitals NHS Foundation Trust, Kris Hutson, Rishi Sharma; Cardiff and Vale University Health Board, James Heyman, Ben Stew; City Hospitals Sunderland NHS Foundation Trust, Chong Kang, Murray Waldron; Countess of Chester Hospital NHS Foundation Trust, Rashid Sheikh, Robert Temple; County Durham and Darlington NHS Foundation Trust, Nav Kara, Holt Waters; Cwm Taf Morgannwg University Health Board, Emma Hallett, Dan Leopard; Doncaster and Bassetlaw Teaching Hospitals NHS Foundation Trust, Aftab Ahmed, Ullas Raghavan, Nicola Stobbs; Dorset County Hospital NHS Foundation Trust, Dario Fradeani, Andrew Lale; East Kent Hospitals University NHS Foundation Trust, Bertram Fu, Henry Sharp, Katherine Steele; East Sussex Healthcare NHS Trust, Paul Kirkland, Agnieszka Litewka, Rishi Vasanthan; Frimley Health NHS Foundation Trust, James Bates, Johnathan Hearn, Roland Hettige, Karen Young; Gloucestershire Hospitals NHS Foundation Trust, Pallavi Agarwal, Charles Hall; Great Ormond Street Hospital for Children NHS Foundation Trust, Ryan Cheong, Richard Hewitt; Great Western Hospitals NHS Foundation Trust, Deepak Gupta, Robert Maweni, Christopher Waters; Guy's and St Thomas' NHS Foundation Trust, Claire Hopkins, Arun Takhar; Hampshire Hospitals NHS Foundation Trust, Thomas Geyton, Afroze Khan; Hull University Teaching Hospitals NHS Trust, Richard Jackson, Patrick Jassar; James Paget University Hospitals NHS Foundation Trust, Sheneen Meghji, Carl Philpott; Lancashire Teaching Hospitals NHS Foundation Trust, Rajeev Advani, John de Carpentier, Antonia Tse; Lewisham and Greenwich NHS Trust, Anastasia Rachmanidou, Abigail Walker; Liverpool University Hospitals NHS Foundation Trust, Ahmed Hussein, Huw Jones, Todd Kanzara, Samuel Leong, Anne Markey, Richard Siau; London North West University Healthcare NHS Trust, Nora Haloob, Anooj Majithia; Medway NHS Foundation Trust, Keli Dusu, Shamim Toma; Mid and South Essex NHS Foundation Trust, Martyn Barnes, George Fayad, Alistair Hardy, Tharsika Myuran, Victoria Perkins, Mark Puvanendran; Mid Cheshire Hospitals NHS Foundation Trust, Chloe Henson, Gopinath Narasimhan, Hussein Walijee; Milton Keynes University Hospital NHS Foundation Trust, Marina Brimioulle, Mark Draper; Newcastle upon Tyne Hospitals NHS Foundation Trust, Sean Carrie, Lepa Lazarova, Janet Wilson; NHS Ayrshire \& Arran, Paul Sooby, Andrew Whymark; NHS Fife, Ross Bannon, David Walker; NHS Grampian, Ram Basakar, Anas Gomati; NHS Greater Glasgow and Clyde, John Frederick Curran, Rhona Hurley, Siew Min Keh, Thushitha
Kunanandam, Louise Melia, Mohd Afiq Mohd Slim, Paul Sooby; NHS Highland, Angus Cain, Fergus Cooper; NHS Lanarkshire, Nick Calder, John Frederick Curran, Katharine E.L. Hamlett; NHS Lothian, Rohit Gohil, lain Hathorn; NHS Tayside, Rasads Misirovs; Norfolk and Norwich University Hospitals NHS Foundation Trust, Andy Bath, Harriet Cuniffe; North West Anglia NHS Foundation Trust, Samuel Dewhurst, Ajmal Masood; Nottingham University Hospitals NHS Trust, Christian Johnatty, Yujay Ramakrishnan; Oxford University Hospitals NHS Foundation Trust, Amberley Munnings, Ali Qureishi; Pennine Acute Hospitals NHS Trust, Samit Ghosh, Anastasia Herman; Portsmouth Hospitals University NHS Trust, Tim Biggs, Harish Viswanathan; Rotherham NHS Foundation Trust, Anas Eldahshan, Miran Pankhania; Royal Berkshire NHS Foundation Trust, Ayeshah Abdul-Hamid, Robert Almeyda; Royal Cornwall Hospitals NHS Trust, Wei Jia, Neil Tan; Royal Devon and Exeter NHS Foundation Trust, Haymar Htun, Mohammed A. Khatwa; Royal Surrey NHS Foundation Trust, Victoria Grammatopoulou, Vishnu Sankalp Sunkaraneni, Karen Young; Royal Wolverhampton NHS Trust, Edward Balai, James Barraclough, Karan Jolly; Salisbury NHS Foundation Trust, Simon Dennis, Emily Lowe; Sandwell and West Birmingham Hospitals NHS Trust, Shubhi Kishwan, Yohanna Takwoingi; Sherwood Forest Hospitals NHS Foundation Trust, Ahmed Shehata, Paraskevi Tsirevelou; Shrewsbury and Telford Hospital NHS Trust, Thomas Saunders, Sevina Tzortzis; Somerset NHS Foundation Trust, Ram Balakumar, Edward Chisholm; South Tees Hospitals NHS Foundation Trust, Mohammed Bahgat, Ravi Kumar, David Whitehead; South Warwickshire NHS Foundation Trust, Husham Barrak, Noor Janjua; St George's University Hospitals NHS Foundation Trust, Tom Jacques; Stockport NHS Foundation Trust, Milan Rudic, Nimisha Vallabh; Swansea Bay University Health Board, Louise Evans; Tameside and Glossop Integrated Care NHS Foundation Trust, Daniela Bondin; The Dudley Group NHS Foundation Trust, Mudit Jindal, Peter Vaida; The Princess Alexandra Hospital NHS Trust, Eleftheria Kiverniti, Zsofia Nemeth; University Hospital Southampton NHS Foundation Trust, Simon Goldie, Phil Harries, Rami Salib; University Hospitals Birmingham NHS Foundation Trust, Ameera Abdelrahim, Shahzada Ahmed, Shahram Anari, Ashraf Mahmood; University Hospitals Bristol and Weston NHS Foundation Trust, Bayo Alli, Claire Langton-Hewer; University Hospitals Coventry and Warwickshire NHS Trust, Dheeraj Karamchandani, Neil McNiven; University Hospitals Dorset NHS Foundation Trust, Poole, Jessica Chapman, Philip Scott; University Hospitals of Derby and Burton NHS Foundation Trust, Nadia Ashraf, Adam Gaunt, Mark Johnston, Joshua Whittaker; University Hospitals of Leicester NHS Trust, Theo Valsamakis, Sophie Wilkinson; University Hospitals of North Midlands NHS Trust, Matthew Isles, Christopher Metcalfe; University Hospitals Plymouth NHS Trust, Hisham Khalil, Oliver Mclaren; West Suffolk NHS Foundation Trust, Laura Leech, David McKiernan; Western Sussex Hospitals NHS Foundation Trust, Michael Robinson, Si- 
mon Watts; Wirral University Teaching Hospital NHS Foundation Trust, Helen Beer, Dilesh Mogre; Worcestershire Acute Hospitals NHS Trust, Charles Daultrey, Nicola Wooles; Wrightington, Wigan \& Leigh NHS Foundation Trust, B. N. Kumar, John Rocke. Data contributors: BMI The Priory Hospital, Birmingham, Neelam Khan; Bolton NHS Foundation Trust, Joshua Simon; Bradford Teaching Hospitals NHS Foundation Trust, Mohammad Adeel; Brighton and Sussex University Hospitals NHS Trust, Imad Amer; Countess of Chester Hospital NHS Foundation Trust, Usama Alkhaddour, Fernando Galli, Shahzad Ghaffar, Manisha Parmar; County Durham and Darlington NHS Foundation Trust, Ashleigh Ivy; Doncaster and Bassetlaw Teaching Hospitals NHS Foundation Trust, Wei S. Leong; East Sussex Healthcare NHS Trust, Dilhara Karunaratne; Gloucestershire Hospitals NHS Foundation Trust, Hiro Ishii, Maryam Nowghani; Guy's and St Thomas' NHS Foundation Trust, Mikkel Alanin, Florian Bast, Benjamin Miller, Carol Xie; Lancashire Teaching Hospitals NHS Foundation Trust, Bhargavi Chandrasekar, Anna Harrison; London North West University Healthcare NHS Trust, Joe Marais; Mid and South Essex NHS Foundation Trust, Jack Gao; Newcastle upon Tyne Hospitals NHS Foundation Trust, Ben Cosway, Hannah Fox, John Hill, Isma Iqbal, Wolfgang Issing, Maliha Kazi, Muhammad Kamal Khan, Umesh Ullal, Mark Williams, Philip Yates; NHS Fife, Kirsten Stewart; NHS Grampian, Kanishka Rao; NHS Tayside, Aaron Ferguson, Peter Ross, Somayyeh Shahsavari, Paul White; Norfolk and Norwich University Hospitals NHS Foundation Trust, Boeke Van Beugen, Ahmad Moinie; Rotherham NHS Foundation Trust, Stuart Richards; Royal Cornwall Hospitals NHS Trust, Elaine Campbell, Evette Grobbelaar; South Warwickshire NHS Foundation Trust, Bimantha Perera; Stockport NHS Foundation Trust, Shameena Shinaz; University Hospitals Birmingham NHS Foundation Trust, Aakash Amlani, Rohan Bidaye, Nur W. Wahid; University Hospitals Bristol and Weston NHS Foundation Trust, Linnea Cheung; University Hospitals of Derby and Burton NHS Foundation Trust, Heather Allen; University Hospitals of North Midlands NHS Trust, Edwin Halliday; Worcestershire Acute Hospi- tals NHS Trust, Sanjay Patel.

\section{Acknowledgments}

Barts Health NHS Trust, Deepak Chandasekharan, Sam Jayaraj; Bedfordshire Hospitals NHS Foundation Trust, Oliver Wakelam; Blackpool Teaching Hospitals NHS Foundation Trust, Meera Brejish, Paul Hans; Croydon Health Services NHS Trust, Giri Wij; Hampshire Hospitals NHS Foundation Trust, Ashok Rokade, Katerina Tsagkovits; Hywel Dda University Health Board, Huw Davies; Imperial College Healthcare NHS Trust, Mustafa Jaafar, Hesham Saleh; Jersey General Hospital, Russell Cathcart; Manchester University NHS Foundation Trust, Rajesh Anmolsingh, Rajiv Bhalla, Fergal Cadden, Sadie Khwaja; Mid Yorkshire Hospitals NHS Trust, Thomas Haigh, Victoria Ward; Northampton General Hospital NHS Trust, Elizabeth Mathews, Mrinal Supriya; Royal United Hospitals Bath NHS Foundation Trust, Stephen McDonald; Torbay and South Devon NHS Foundation Trust, Rachel Easto, Chris Potter; Walsall Healthcare NHS Trust, Ahmad Abou-foul, Mark Simmons; Warrington \& Halton Hospitals NHS Foundation Trust, Hannah Emerson, Hemal Raja; York Teaching Hospital NHS Foundation Trust, Dare Oladokun.

\section{Funding}

None declared.

\section{Ethics approval and consent to participate}

Not applicable.

\section{Consent for publication}

Not applicable.

\section{Availability of data and materials}

Not applicable.

\section{Conflict of interest}

None declared.

\section{References}

1. Federation of Surgical Specialty Associations. Clinical guide to surgica prioritisation during the coronavirus pandemic. Available from: https://fssa.org uk/_userfiles/pages/files/covid19/prioritisation_master_240820.pdf (Last Accessed 10th January 2021)

2. ENT UK. Clinical guide to surgical prioritisation during the coronavirus pandemic (ENT specific). Available from: https://www. entuk.org/clinical-guide-surgical-prioritisation-during-coronavirus-pandemic-entspecific (Last Accessed 10th January 2021).

3. Zhu W, Huang X, Zhao H, Jiang X. A COVID19 patient who underwent endonasal endoscopic pituitary adenoma resection:
A case report. Neurosurgery 2020; 87(2) E140-E146.

4. Workman AD, Welling DB, Carter BS et al Endonasal instrumentation and aerosolization risk in the era of COVID19: simulation, literature review, and proposed mitigation strategies. Int Forum Allergy Rhinol 2020; 10(7): 798-805.

5. United Kingdom Government Website GOV.UK. Coronavirus (COVID-19) in the UK. Available from: https://coronavirus.data.gov. uk/ (Last Accessed 10th January 2021).

6. NHS England. Consultant-led Referral to Treatment Waiting Times Data 2020-21. Available from: https://www.england.nhs uk/statistics/statistical-work-areas/rtt-waiting-times/rtt-data-2020-21/ (Last Accessed 10th January 2021).

7. Royal College of Surgeons of England. Recovery of surgical services during and after COVID-19. Available from: https:// www.rcseng.ac.uk/coronavirus/recoveryof-surgical-services/ (Last Accessed 10th January 2021).

8. NHS England. NHS roadmap to safely bring back routine operations. Available from: https://www.england.nhs.uk/2020/05/ nhs-roadmap/ (Last Accessed 10th January 2021).

9. Royal College of Surgeons of England. Survey findings: Elective surgery during COVID-19. Available from: https://www. rcseng.ac.uk/news-and-events/news/ archive/survey-results-elective-surgery- 
under-covid/ (Last Accessed 10th January 2021).

10. Wickham H, Averick, M, Bryanm J et al. Welcome to the tidyverse. Journal of Open Source Software 2019; 4(43): 1686.

11. Subirana I, Sanz H, Vila J. Building Bivariate Tables: The compareGroups Package for R. J Statistical Software 2014; 57(12): 1-16.

12. Wickham H, François R, Henry L, Müller K. dplyr: A Grammar of Data Manipulation. Available from: https://CRAN.R-project.org/ package $=$ dplyr. (Last Accessed 10th January 2021).

13. Wickham H. ggplot2: Elegant Graphics for Data Analysis. 2nd ed. New York: SpringerVerlag, 2016

14. Grolemund G, Wickham H. Dates and Times Made Easy with lubridate. Journal of Statistical Software 2011;40(3): 1-25.

15. United Kingdom Government Website: GOV.UK. Population of England and Wales. Available from: https://www.ethnicityfacts-figures.service.gov.uk/uk-population-by-ethnicity/national-and-regionalpopulations/population-of-england-andwales/latest\#: :text=48.2\%20million\%20 people\%20(86.0\%25),White\%20ethnic\%20 group\%20(4.4\%25) (Last Accessed 3rd March 2021).

16. American Society of Anesthesiologists ASA Physical Status Classification System. Available from: https://www.asahq.org/ standards-and-guidelines/asa-physicalstatus-classification-system (Last Accessed 10th January 2021).

17. UK Office for National Statistics. Population estimates for the UK, England and Wales, Scotland and Northern Ireland: mid-2019. Available from: https://www.ons.gov.uk/ peoplepopulationandcommunity/populationandmigration/populationestimates/ bulletins/annualmidyearpopulationestimates/mid2019estimates (Last Accessed 10th January 2021).

18. Federation of Surgical Specialty Associations. Clinical Guide to Surgical Prioritisation During the Coronavirus Pandemic. Available from: https://fssa. org.uk/covid-19_documents.aspx (Last Accessed 10th January 2021).

19. Brożek JL, Bousquet J, Agache I et al. Allergic Rhinitis and its Impact on Asthma (ARIA) guidelines-2016 revision. J Allergy Clin Immunol 2017; 140(4): 950-958.

20. Saxena A, Nekhendzy V. Anesthetic considerations for functional endoscopic sinus surgery: a narrative review. Journal of Head \& Neck Anesthesia 2020; 4(2): e25.

21. Reitsma S, Lund VJ, Carrie S, Fokkens WJ. ERS member survey on COVID-19 symptomatology and personal protection: a construct to predict early COVID-19 disease. Rhinology Online 2020; 3: 31-37.

22. Dehgani-Mobaraki P, Kamber Zaidi A, Levy JM. Face masks are an essential tool to mitigate the ongoing SARS-CoV-2 pandemic: a call to action. Rhinology Online 2020; 3 : 157-159.

23. Public Health England. COVID-19: Guidance for the remobilisation of services within health and care settings: Infection prevention and control recommendations. Available from: https://assets.publishing.service.gov.uk/government/uploads/system/ uploads/attachment_data/file/910885/ COVID-19_Infection_prevention_and_control_guidance_FINAL_PDF_20082020.pdf (Last Accessed 10th January 2021).

24. Van Gerven L, Hellings PW, Cox T et al. Personal protection and delivery of rhinologic and endoscopic skull base procedures during the COVID-19 outbreak. Rhinology 2020; 58(3): 289-294.

25. Kamel R, Ragab A, Abdelghaffar $\mathrm{H}$ et al. Safe practice guidance: a review for otorhinolaryngologists during COVID-19 pan- demic and after reopen process. Rhinology Online 2020; 3: 128-140.

26. Hopkins C, Browne JP, Slack R et al. Complications of Surgery for Nasal Polyposis and Chronic Rhinosinusitis: The Results of a National Audit in England and Wales. Laryngoscope 2006 Aug; 116(8): 1494-1499.

27. Hosemann W, Draf C. Danger points, complications and medico-legal aspects in endoscopic sinus surgery. GMS Curr Top Otorhinolaryngol Head Neck Surg 2013; 12: Doc06.

28. Coughlan E, Nafde C, Khodatars S et al. COVID-19: lessons for junior doctors redeployed to critical care. Postgrad Med J 2020; 0: 1-4.

29. Joint Committee of Surgical Training. Maximising Training Opportunities. Available from: https://www.jcst.org/keydocuments/ (Last Accessed 10th January 2021).

\section{Sridhayan Mahalingam}

Department of Otolaryngology

Guy's and St Thomas' NHS Founda-

tion Trust

Great Maze Pond

London, SE1 9RT

United Kingdom

E-mail: s.mahalingam@nhs.net

ISSN: 2589-5613 / @2021 The Author(s). This work is licensed under a Creative Commons Attribution 4.0 International License. The images or other third party material in this article are included in the article's Creative Commons license, unless indicated otherwise in the credit line; if the material is not included under the Creative Commons license, users will need to obtain permission from the license holder to reproduce the material. To view a copy of this license, visit http://creativecommons.org/ licenses/by/4.0/ 


\section{APPENDICES}

Appendix 1. Questionnaire.

$\stackrel{\text { BRS }}{2}$ Thank you for participating in this audit. Please select all that apply for each question

Name of NHS Hospital

Name of person entering information:

Patient Demograahics

Age (years)

Gender: $\quad \square$ Male $\quad$ Female

Ethnicity: $\quad$ White

White
South Asian (Indian, Pakistani, Bangladeshi)

outh-East Asian (Chinese, Korean)

$\begin{array}{ll}\text { Mixed } & \text { Please state } \\ \text { Other } & \text { Please state } \\ & \end{array}$

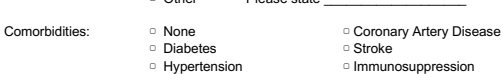

Hypertension
Other. Please state $\quad$ Immunosuppression

Anaesthetic performance status (I-V):

Pre-operative management

For how long did patient self-isolate prior to surgery?

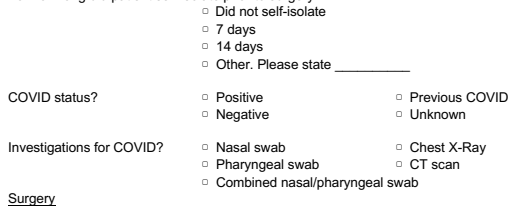

Surgery

Diagnosis

Name of procedure

Date of procedure

Setting of surgery:

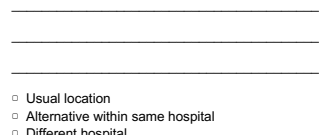

Alternative within same hospita

Is this a "COVID-free" site? प Yes a No

BRS/BRSJ COVID Study 2020

$\stackrel{\text { BRS }}{c_{1}}$

\section{Procedure}

Instruments used:

Cold Steet

$\begin{array}{ll}\text { Cold Steel } & \text { Drill } \\ \text { Microdebrider } & \text { Electrocautery }\end{array}$

Duration of general anaesthesia: $\quad \square \leqq 60$ minutes

$121-180$ minutes

$>180$ minutes

Any changes in anaesthetic/surgical technique/practice?

\begin{tabular}{l} 
Please comment: \\
\hline
\end{tabular}

Are you utilising any additional steps to mitigate against viral transmission?

Please comment:

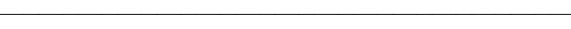

Any challenges in performing surgery?
Please comment:

Intra-operative complications? $\quad$ Yes

Please comment:

\begin{tabular}{l}
\hline Yes \\
Return to theatre?
\end{tabular}

If yes, please state reason:

th of inpatient stay: $\quad \square \leqq 12$ hours

\12 hours

$24-48$ hours
Over 48 hours. Please state

Delayed discharge?
If yes, please state reason:
$\underset{B R S}{\stackrel{5}{B R S}}$
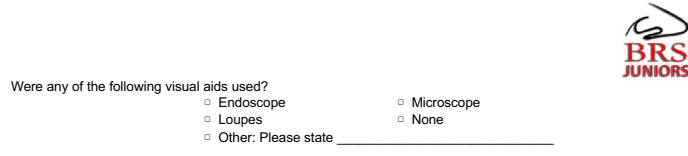

Tear

Anaesthetist: $\quad \begin{aligned} & \square \text { Regular } \\ & \square \text { Unfamilit }\end{aligned}$

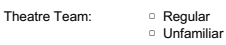

$\begin{array}{ll}\text { Trainee Involvement: } & \begin{array}{l}\text { No trainee present } \\ \text { Obberved } \\ \text { Assisted }\end{array}\end{array}$

PPE Used by Surgical Team:

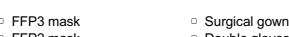

PAPR Hood

Oxygen tent

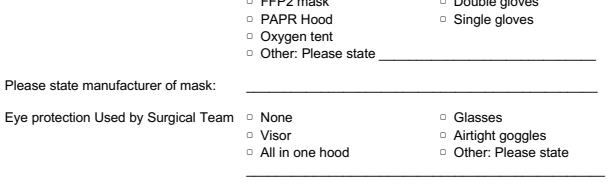

Please state manufacturer of eye protection equipment

Was it possible to see adequately?

PPE Used by Anaesthetic Team:

\begin{tabular}{|c|c|}
\hline $\begin{array}{l}\text { FFP3 mask } \\
\text { FFP2 mask } \\
\text { PAPR Hood } \\
\text { V Visor } \\
\text { Oxygen tent }\end{array}$ & $\begin{array}{l}\text { Surgical gown } \\
\text { D Duble gloves } \\
\text { O Single gloves } \\
\text { D isposable hood } \\
\text { other: Please state }\end{array}$ \\
\hline $\begin{array}{l}\text { FFP3 mask } \\
\text { FFP2 mask } \\
\text { PAPR Hood } \\
\text { Visor } \\
\text { Oxygen tent }\end{array}$ & $\begin{array}{l}\text { Surgical gown } \\
\text { Double gloves } \\
\text { S Single gloves } \\
\text { Disposable hood } \\
\text { - Other: Please state }\end{array}$ \\
\hline
\end{tabular}

BRS/BRSJ COVID Study 2020

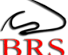

BRS

Follow-up (3 weeks)

Patient complications?
If yes, please state.

as patient subsequently found to be COVID +ve?

$a$ No
$\square$ Confirmed CovID

Confirmed COVID

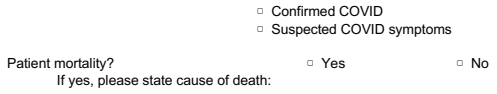

If yes, please state cause of death:

the three weeks following surgery are you aware of?

a. Staff morbidity/COVID Cases in theatre team?$$
\text { None }
$$

Surgical team

b. Did the operating surgeon or assistant develop COVID symptoms or test positive?

No
Yes. Please give details

Thank you for completing this questionnaire. Please feel free to state any further comments 
Appendix 2. Operative procedure categorisation

\section{Operative procedure category Type of operation}

Diagnostic

1. Examination under Anesthesia

2. Biopsies

3. Unilateral procedure for diagnostic purposes ie unilateral sphenoidotomy

Functional

1. FESS

2. Septoplasty or Septorhinoplasty due to obstruction only

3. CSF leak repair

4. Hypophysectomy for decompression

Cancer

1. Confirmed sinonasal or skull-based malignancy

Other

Other procedures 